\title{
Research on Training Mode and Paths for Autonomous Professional development of Foreign Language Teachers in Colleges and
}

\section{Universities}

\author{
Hao Jingjing \\ Foreign Language College, Qilu Normal University Jinan, Shandong, 250013
}

Keywords: Foreign language teachers in colleges and universities; autonomous learning; foreign language major; training mode; teaching

\begin{abstract}
Autonomous professional development is the inevitable trend requirements of complying with the current colleges and universities to improve the development mechanism of disciplines of foreign language major in colleges and universities. This kind of autonomous professional development mode is the training mode of lifetime professional consciousness, autonomous training mode for foreign language teachers is the lifelong professional consciousness accompanying whole process of teachers' whole teaching career. Under this training mode, teachers are more concerned about the reform and thinking of disciplines of foreign language major, but also need the teachers with autonomous and practical teaching ability, and the autonomous professional development conscious. Based on this, by mainly focusing on taking the current mode of foreign language major autonomous development in colleges and universities as elaboration perspective, this paper analyzes existing problems and discusses about the effective ways to promote the practice ability of foreign language teaching and autonomous professional development of teachers.
\end{abstract}

\section{Introduction}

The autonomous learning has always been the focus concern of foreign language education sector, and it has gradually become a hot subject in recent years. At present, one of the most important goals in the study of foreign language courses under the college and university teaching environment is to cultivate students' autonomous learning ability. However, at the same time of highly emphasizing college students' autonomous learning and self-cultivated professional ability, as a professional teacher team, how to improve the autonomous learning and the autonomous professional development of teachers' foreign language major is undoubtedly one of the key practical problems concerned in the development of foreign language education. Due to the lack of autonomous teachers, it is difficult to achieve strong guidance on the phenomenon that students lack the concept of autonomous foreign language learning. The teacher professional team is the guider of teaching and guiding students, if the teacher's own professional ability is not strong enough, it will inevitably affect teaching quality of teaching foreign language teaching. However, in the previous field of foreign language education, little attention has been paid to the autonomous professional development of the teachers' team. Therefore, in order to guarantee the foreign language teaching quality in colleges and universities, and improve implementation effect of foreign language course teaching, it is essential to improve the autonomous professional development ability and teaching practicability of teachers' team, because the teachers' autonomous learning ability of foreign language major is the important way to guarantee the improvement of students' autonomous learning quality. Therefore, this paper will explore the training mode and ways of autonomous development of foreign language teachers in colleges and universities, focusing on the study pay attention to and study. 


\section{Analysis of main issues on autonomous professional development of foreign language teachers in colleges and universities}

The improvement of the foreign language teacher' practice teaching ability requires teachers' team to be autonomous and self-discipline, by taking self-development as an opportunity, emphasizing the cultivation and promotion of self -professional teaching ability in practical teaching. Through the thinking, reflection and improvement of dynamic teaching practice, and improvement of teaching ability and other links to constantly improve foreign language teaching, thus to promote autonomous professional development of teachers. In the big trend of social development based on the global knowledge economy as the core, the rapid development of the global economy is bound to raising a serious challenge for cultivating the foreign language talents in colleges and universities. In the future, the focus of development of foreign language education in colleges and universities will be the cultivation of the comprehensive practical ability and the autonomous learning ability of foreign language talents. In the face of the fact that the development of foreign language education, the role of foreign language teachers in colleges and universities also undergoes a fundamental change, which is more concerned about the comprehensive study of students, the improvement of practical ability and the cultivation of autonomous learning ability. However, in order to achieve the important change of the teaching role of teachers, the team of foreign language teachers must have self-development motivation and autonomy learning ability, thus to better meet the challenges and give students more teaching guidance and assistance support in class practice teaching, the theoretical knowledge and practical experience of autonomous learning, meeting the social demand for the improvement of the quality of foreign language talents. However, the current team of foreign language teachers in colleges and universities lack awareness of autonomous learning, and there are several issues on the autonomous development training mode of teachers as follows.

The professional development consciousness of foreign language teachers mainly refers to the awareness level of evaluation of curriculum teaching results, and changes of the unfavorable status. The foreign language autonomous conscious also includes awareness planning of the development state of current major, and the autonomous development of the ability of the future major. The development planning of domestic foreign language teachers is still stranded in improvement of the professional level, but too little attention is paid to the key position and guidance role of the foreign language teachers' team in the professional development. Similarly, the requirements proposed by colleges and universities for foreign language teachers are also more concerned about the development of the school itself. This makes a lot of teachers have the wrong concept on the autonomous professional development and improvement and believe that the administrative function units are responsible for the development of foreign language major. Therefore, the autonomous professional development of foreign language teachers has always been in a passive state, when teachers are in the face of difficult problems of teaching, their autonomous development conscious is weak, and this will inevitably affect the problems generated in teaching practice. The stronger autonomous development conscious of teachers, the higher autonomous development ability of teachers, teachers can calmly face different complex teaching patterns and teaching environment, with strong adaptability. In order to have the teaching beliefs of overcoming heavy resistance when encountering more teaching practice problems, thereby eliminating all difficulties, and willing to put more energy to stimulate the greater power practice to strengthen their foreign language level and autonomous development conscious.

According to a large-scale questionnaire survey of the foreign language major in colleges and university, the research results of scientific research projects in China is still undesirable. Among them, the probability of publication of professional papers with the professional level should be improved. Meanwhile, the specific research methods and ideas are relatively backward, showing the relatively weak professional disciplines and interdisciplinary contact, including the teacher team planning is not mature and systematic, etc. It can be said that the scientific research results related 
to the foreign language major have many problems, which are mainly related to the relatively late development of China's foreign language major. Nowadays, the society is making continuous progress, the development trend and requirement of education is improved accordingly. The systematic planning of teacher team teaching practical career of the autonomous development of the foreign language major needs to be strengthened. On the one hand, the improvement of scientific research results of foreign language major is an important way to promote the improvement of teaching quality of foreign language teacher team and comprehensive professional ability of teachers. On the other hand, through the remarkable improvement of scientific research ability of foreign language major, teachers' team can abandon mechanized teaching model in the past teaching practice, and gradually reform the practice of teaching, thus to adapt to the improved mechanism requirement of autonomous development of current foreign language major.

Since there's the continuous improvement of demand for the foreign language talents due to the global social development currently, the teacher team of foreign language major in colleges and universities has also been defined as an important teaching team of HR teachers. At the same time, the scale of college enrollment has been gradually expanded in recent years, the annual enrollment of the professional students has continued to increase, and the classes supporting foreign language major has also been developed to the trend of constant expansion. There's the significant increase in teaching hours of foreign language class and college English class, the division of the foreign language class is more specific. As a result, the volume of teachers' lesson preparation and the workload of the familiarity of the new curriculum have been increased significantly. In this long years of the repeated and monotonous teaching practice mode, the teaching task indicators of the teacher team has become more and more difficult to fully realize. Many teachers are overwhelmed by the heavy task of teaching pressure, and it is difficult to cultivate autonomous development conscious and reflective consciousness, which is conversely reduced greatly. It's difficult to do a good combination of teaching and scientific research and promote each other, and their teaching enthusiasm has been gradually consumed, the teachers have little time to systematically and autonomously complete the foreign language learning in the usual class. If the pressure of foreign language teachers is not relieved over a long period of time, it will result in burnout. This phenomenon of teaching burnout caused by foreign language teachers is very common in colleges and universities, which is largely manifested in the lack of teachers' enthusiasm, lack of autonomy of learning conscious and work initiative, there's no sense of accomplishment and objective problem for perfunctory teaching in order to achieve the teaching goal.

\section{Discussion on effective ways for autonomous professional development of foreign language teachers in colleges and universities}

The long-term establishment of the autonomous professional development mechanism of foreign language teachers in colleges and universities not only requires teachers to have high level of knowledge and skills, but also pays attention to the teaching reflection of classroom teaching practice. Teachers' autonomous professional development requires teachers to have regular and comprehensive reflection according to their classroom teaching practice process, teaching methods, teaching behavior and the teaching effect obtained. The process of reflection is the process for teachers to have active and initiative discovery of problems, problem solving and improvement of the teaching. It is a process of strengthening professional sense, sense of responsibility, establishing personal beliefs, stimulating creativity and encouraging the individual professional development of teachers. Teachers' reflection behavior, reflection habits and reflective ability are not only an important way for the teachers to develop autonomous majors, but also enable teachers to learn to reflect, and learn to think, and learn autonomous learning, thus to constantly improve teaching methods, improving teaching, improving teaching ability, promoting autonomous professional development. For example, in the foreign language teaching practice stage, the attention should be paid to construction of situational teaching, cooperative teaching and other research modes. The 
basic elements for the construction of situational teaching need teachers to combine the teaching mode to guide the study. Similarly, the cooperative learning is also the learning mode for a teacher to give a thematic classroom research by combing with a teaching background. For example, the real teaching cases are used to conduct the interactive teaching by surrounding the teaching objectives, and propose to establish sound classroom learning atmosphere through effective issues, to discuss in form of groups, multimedia and other integrated application methods for teaching. In this way, students can establish the confidence of learning, and gradually enhance self-thinking, self-learning ability through powerful environment of situational teaching. However, the teachers must be based on the requirements of foreign language practice teaching to achieve this process, giving a profound reflection on more teaching methods, thus to reach the important purpose of selfimprovement of foreign language ability through the improvement of teaching practice, thereby promoting autonomous professional development.

In traditional teaching model, the teachers only follow the teaching plan to practice classroom teaching, and complete the teaching task in prescribed class hour schedule. However, this process lacks the re-examination and cognition of the teaching essence and the teaching process, and awareness of self-decision making, self-professional ability, and self-renewal ability are relatively weak. Therefore, there's great difference in the result of teaching practice and the actual teaching target, teaching theory and teaching practice cannot be combined organically to promote each other. From the perspective of teachers, the repeat and mechanical work day after day, year after year becomes boring and ineffective, the passion for teacher's career and the fighting for self-promotion is slowly subsided, and it seems difficult to cross the gap between theory and practice, teaching and scientific research. In the 1980s, the action research introduced to the field of education liberated the majority of teachers. The teachers become the researchers of their own teaching, becoming active from passive, initiative and active participation in teaching research, reflecting the teaching process, critical thinking of teaching problems and creative development of teaching theory. In this way, the teaching process of the teachers becomes the process of self-reflection, self-education, selflearning, self-improvement and self-development. For example, in the classroom teaching practice, teachers should be able to actively develop effective teaching strategies through the analysis and study of teaching theory, and to change the role of pure knowledge communicators in the past. The teachers should be able to integrate the professional theory and teaching practice behavior of foreign language knowledge. In the process of carrying out the action research, foreign language teachers in colleges and universities should take the method of "learning" while "research" to combine "action" with "research", thus to realize the sustainable development of their own profession through research, exploration and reflection.

It's necessary for foreign language teachers in colleges and universities to think deeply about the teaching practice behavior of their profession, the whole teaching process, and construction of the teaching target and others. There are different professional characteristics between foreign language teachers and teachers of other disciplines, and the foreign language teachers will encounter various problems in practical teaching process. This requires foreign teachers not only to pay attention to the study of individual foreign language theory, but also to actively change the traditional passive teaching methods to learn the content of related disciplines, such as Pedagogy, Psychology, second language acquisition, teaching method, education action research and other interdisciplinary knowledge. Foreign language teachers should make full use of modernized educational information technology to enhance professional quality, and cultivate autonomous professional development awareness. The key for the autonomous professional development of foreign language teachers in colleges and universities is that the teachers have autonomous conscious and the ability of autonomy. Namely, the ability to consciously be responsible for their professional development, autonomous learning process, and the ability to carry out the decisionmaking of teaching process, teaching environment and so on. For example, the teachers not only need to focus on improvement of situational teaching, cooperative mechanism teaching, effective 
questioning teaching mode and others through the reform and innovation of teaching practice mode, but also the professional learning of foreign language teachers also need to have the in-depth understanding of the essence of language development, international cultural differences and others. To this end, teachers must have the professionalism of lifelong autonomous learning, and they can be good at evaluating each stage of professional learning. In such special foreign language learning environment of China, there are very tense classes for foreign language major, students have more learning pressure. Based on this, teachers should focus on full lesson preparation and autonomous learning after class while being able to change the innovation model of teaching practice, thus to improve the level of acute professional judgment ability, promoting the unprecedented improvement of their own foreign language professional theory, practice level, and professionalism.

\section{Conclusion:}

Autonomous professional development of foreign language teachers in colleges and universities is a long-term, continuous and progressive process. This requires teachers to establish a lifelong learning concept and autonomous learning conscious in their own career, thus to gradually improve their own quality and professionalism. In addition to complete the basic teaching task, foreign language teachers in colleges and universities should also pay attention to the autonomous learning process of their own foreign language major, focusing on emphasizing the use of in-depth integration of teaching practice and professional knowledge. Meanwhile, the teachers should have an in-depth understanding of regional and cultural differences of foreign language, and others, thus to have a more in-depth understanding of foreign language major, to avoid burnout psychological emotions caused by the mechanized teaching patterns. However, the factors affecting foreign language teachers' professional development are also multidimensional, and there's the need to combine their internal development factors with external support such as society, schools and families. In this way, the foreign language teachers in colleges and universities can improve teaching level in the process of reflecting the autonomous learning and teaching practice, and constantly re-examining themselves, establishing confidence, easing physical and mental stress, promoting "mutual benefit and win-win" between teachers and students, so as to reverse the boring passive learning atmosphere of the traditional foreign language teaching, promoting the sustainable development of long-term mechanism of foreign language major.

\section{Acknowledgment}

Project: One of Research Results of Annual Topic of Shandong Provincial Humanistic and Social Science - " Reflective Teaching Practice and Study on University Foreign Teacher's Professional Development from a Research Perspective. Project number: 15-ZC-JY-08.

\section{Reference}

[1] Wu Han. The current situation and Countermeasures of foreign language teachers' professional development in Colleges and universities [J]. China foreign language 2011.4

[2] Dong Jinwei. Learning strategies to promote the professional development of College English teachers: An Empirical Study on [J]. foreign language teaching theory and practice in G University 2012.2

[3] Wang Qiang; Zhang Hong. [M]. English teachers' action research in Beijing: foreign language teaching and Research Press, 2014

[4] Cao Minjie. On the training of young foreign language teachers in Colleges and universities [J]. China higher education research 2001.8 